\title{
«Todos unidos triunfaremos...». Nuevas dificultades para la unidad electoral peronista*
}

«All united we will triumph...» New obstacles

for the peronist electoral unity

\section{RODRIGO ZARAZAGA S.J.}

Centro de Investigación y Acción Social (CIAS)

Consejo Nacional de Investigaciones Científicas y Técnicas, Argentina

rodrigo.zarazaga@cias.org.ar

Desde la crisis de 2001 hasta la actualidad, el peronismo no se ha presentado unificado en ninguna elección presidencial. El presente artículo indaga sobre las causas de dicha falta de unidad. Se sostiene que la base tradicional del voto peronista ha sufrido una progresiva fragmentación social, la cual explica la diversa oferta electoral de dicho partido. Analizando diferentes bases de datos se ofrece evidencia de dicha fragmentación asi como del impacto electoral de la misma, haciendo foco en tres dimensiones de los votantes: condición laboral, percepción de planes sociales y marginación en el hábitat.

\section{Introducción}

«Todos unidos triunfaremos», reza un verso de la histórica marcha del Partido Justicialista. Sin embargo, desde 2003 hasta la fecha, en ninguna elección presidencial el peronismo logró ir unificado apoyando a un solo candidato. En 2015 perdió las elecciones presidenciales, a pesar de que entre los tres candidatos peronistas que se presentaron sumaban más del $60 \%$ de los votos. El presente artículo se propone indagar acerca de si la falta de unidad peronista en las elecciones se debe fundamentalmente a un problema de liderazgo de sus candidatos o a un problema estructural de la sociedad argentina. Nuestra hipótesis es que la base social del voto peronista ha sufrido una progresiva fragmentación que explica la diversa oferta electoral de dicho partido.

Artículo aceptado para su publicación el 30 de abril de 2019.

El autor agradece a Juan Germano de Isonomía Consultores y Gustavo Marangoni de M y R Asociados, por compartir bases de datos y generosamente incorporar las preguntas relevantes a este estudio en sus encuestas. Asimismo agradece a Gonzalo Elizondo por su invalorable asistencia técnica y a Lucas Ronconi cuyos comentarios y consejos ayudaron a mejorar notablemente la calidad de este artículo. 
El 22 de noviembre de 2015, Mauricio Macri, candidato de la alianza Cambiemos, resultó electo Presidente en lo que fue el primer balotaje de la democracia argentina. Para sorpresa de muchos, por primera vez en la historia un candidato de un partido catalogado como de derecha o centro-derecha, accedía al poder en elecciones libres y democráticas. Ya en las elecciones generales del 25 de octubre de ese mismo año, la candidata de Cambiemos, María Eugenia Vidal, había resultado electa Gobernadora de la Provincia de Buenos Aires. Además, candidatos de Cambiemos habían triunfado en once municipios del Conurbano Bonaerense, algunos de ellos tradicionales bastiones peronistas como Berisso, Lanús, Tres de Febrero y San Vicente.

$\mathrm{Al}$ reiterarse en 2017, en las elecciones de medio término, una victoria de Cambiemos, algunos autores comenzaron a plantear la posibilidad de que se estuviera gestando una nueva hegemonía capaz de eclipsar al peronismo. Opinaban también que dicha hegemonía contaba con el apoyo de sectores medios bajos de trabajadores tradicionalmente peronistas, que afectados por el impuesto a las ganancias votaban ahora por Cambiemos (Natanson, 2017; Semán, 2017). En sintonía con estos análisis propuse la existencia de una creciente fragmentación de la base del voto peronista: «el peronismo históricamente tuvo un núcleo fuerte en el mundo del trabajo organizado, y hoy, ese mundo está dividido en dos. [...] Muchas veces el tipo que está en el piquete y el que maneja el taxi y se enoja porque no lo dejan pasar - los dos- se consideran peronistas y uno está pidiendo por trabajo y el otro quiere que le metan bala» (Zarazaga, 2017). Una explicación semejante sostuvo luego Juan Carlos Torre, en su actualización del clásico Los huérfanos de la política de partidos: «Para resumir el argumento que quiero explorar anticipo una conjetura: la candidatura de Cristina y la candidatura de Massa son la expresión bastante representativa de dos fragmentos en los que están divididas las bases populares del peronismo» (2017).

Esta hipótesis, que sostiene que el peronismo enfrenta un escenario desconocido por la fragmentación de su base de apoyo tradicional, fue bien recibida (Fidanza, 2017; Murillo, 2017), pero también rápidamente discutida. Julio Burdman respondió que se trataba de un problema de falta de liderazgo, no de separación en las bases: «...el peronismo siempre tuvo esa doble apelación hacia los que están muy abajo y hacia los que están en la vía intermedia. Y nunca funcionó mal» (Burdman, 2017). Marcos Novaro agregó a esta crítica una pregunta válida: «¿Hay alguna evidencia de que, por ejemplo, los sindicalizados votan más a Massa y los informales y desocupados a Cristina? No» (Novaro, 2017). El presente artículo pretende justamente responder a esas dos preguntas: chay evidencia de que la base del peronismo esté hoy más dividida que otrora? Y si así fuera, ¿cómo se expresa dicha fractura social y electoralmente? Nuestra hipótesis es que la exclusión social, que se expresa en 
múltiples dimensiones (dependencia social, condición laboral, hábitat, vivienda, educación, etc.) y que alcanza a un tercio de la población, implica la fragmentación de la clase trabajadora lo que afecta electoralmente al peronismo más que a ningún otro espacio político. En pocas palabras el peronismo es víctima de la verdadera grieta argentina, la grieta social.

Sostenemos que, a partir de 2001, se cristalizan diversas discontinuidades sociales que fragmentan la sociedad salarial de la que emergió el peronismo y que esto tiene consecuencias en las preferencias electorales de la base tradicional del voto peronista. Esta fragmentación social no solo explica la «grieta» entre Cambiemos y el Kirchnerismo, sino también la fractura ad intra del peronismo. Las clases baja y media baja constituyeron históricamente la base del voto peronista, pero la primera hoy vota fundamentalmente al Peronismo K, mientras que la segunda muestra preferencias por Cambiemos o el Peronismo no K. Llamativamente el votante del Peronismo no K tiene características sociales más parecidas al de Cambiemos que al del Peronismo K. La base histórica del peronismo está dividida y muestra diferentes preferencias electorales ${ }^{1}$.

La marginación social se expresa en múltiples dimensiones, pero como nos excede estudiar el impacto electoral de cada una de ellas, nos centramos en la condición laboral, la percepción de planes sociales y la marginación en el hábitat. Sostenemos que dentro de la base histórica del voto peronista los sectores más marginados en alguna de estas tres dimensiones tienden a votar más por el Peronismo K y los menos marginados por Cambiemos o el Peronismo no K.

El artículo está organizado como se detalla a continuación. El primer punto describe la evolución social de las bases históricas del peronismo haciendo foco en su progresiva fragmentación, especialmente a partir de la crisis de 2001, y el segundo punto analiza diferentes bases de datos para dar cuenta del efecto de dicha fragmentación sobre el voto. Concluye sugiriendo posibles escenarios electorales a futuro y algunas avenidas para avanzar en esta línea de investigación.

\section{Evolución de la base histórica del peronismo}

El proceso, iniciado en los años 30, de industrialización y desplazamiento demográfico hacia las fábricas y centros urbanos estableció el esce-

Por Peronismo K, PJ K o FPV nos referimos indistintamente a quienes expresaron votar al Frente para la Victoria en 2015 y Unidad Ciudadana en 2017. Nos referimos indistintamente con los términos Peronismo no K o PJ no K a quienes expresaron votar en 2015 por Unidos por una Nueva Alternativa (Sergio Massa) o Alianza Compromiso Federal (Adolfo Rodriguez Saá) y en 2017 por 1País (Sergio Massa) o Cumplir (Florencio Randazzo). Para más detalle ver Apéndice. 
nario en el que se desarrolló el peronismo. Nacido de la creciente pujanza de la clase obrera dentro de la economía nacional, su ideario procuraba darle participación política al mundo del trabajo organizado. Desde el 17 de octubre de 1945, y como fruto del accionar previo de Juan Domingo Perón desde la Secretaría de Trabajo, el programa peronista quedó atado a la defensa de los derechos de los trabajadores y al ideal del pleno empleo (Colazingari y Palermo, 2016).

Entre 1943 y 1946 el número de trabajadores con seguridad social se triplicó y volvió a hacerlo en 1952, alcanzando por primera vez a más del 70 $\%$ de los trabajadores (Collier y Collier, 1991). Los trabajadores sindicalizados se quintuplicaron entre 1945 y 1954 constituyendo la columna vertebral del movimiento liderado por el Gral. Juan Domingo Perón, sin perjuicio de que otros actores y sectores también lo apoyaran. Juan Carlos Torre destaca «el sobredimensionamiento del lugar político ocupado por los trabajadores organizados, quienes pasaron de ser una pieza importante pero complementaria en un esquema de orden y paz social, a convertirse en el soporte principal de la fórmula política de Perón» (Torre, 2012:142). El lugar privilegiado del sindicalismo en el movimiento se muestra en que Perón le otorgara a este un tercio de los cargos electivos, y en que sindicalistas como Ángel Borlenghi (Ministro del Interior), Atilio Bramuglia (Ministro de Relaciones Exteriores) o José María Freire (Ministro de Trabajo y Previsión), entre otros, ocuparan cargos relevantes en el Ejecutivo Nacional.

El mundo del trabajo organizado se constituyó desde entonces en la principal fortaleza electoral del peronismo. Esto no solo fue cierto en las victorias electorales de 1946, 1952 y 1973 (en las que Perón obtuvo 53 \%, 62 \% y 63 \% de los votos, respectivamente), sino también en las elecciones posteriores a la dictadura militar, en las que el peronismo no siempre salió triunfante. En 1983, el sindicalismo no resignó su rol en el peronismo e impuso su peso en la selección de candidatos y la conducción de la campaña. Raúl Alfonsín triunfó en esas elecciones presidenciales consiguiendo un notable $27 \%$ de votos entre los trabajadores no capacitados (Catterberg y Braun, 1989)².

Según Catterberg (1985), ya en 1983 se da una configuración social distinta en la que una parte de los sectores bajos estructurados, anteriormente peronistas, votan por Alfonsín. Pero Catterberg se refiere a trabajadores formales, propietarios de su vivienda y con expectativas altas de ascenso social: «...obreros especializados, técnicos y supervisores, empleados, vendedores y trabajadores semiespecializados de servicios tuvieron un comportamiento electoral diferente al de los obreros sin calificación y trabajadores de servicios no especializados». El autor marca la ruptura de los obreros capacitados en sus preferencias electorales con los no capacitados. Nosotros marcamos el crecimiento del sector excluido en los 90 que terminará desarrollando en las décadas siguientes intereses y preferencias electorales distintas a las del movimiento obrero organizado. Dicho sector no es considerado por Catterberg en el 1983 de manera específica sino subsumido con los obreros poco calificados. 
Pero, de todos modos, el $70 \%$ de estos trabajadores votó por el candidato peronista, Ítalo Luder. La ley de tercios mantuvo su vigencia entre 1983 y 1987, proviniendo del sindicalismo más de un cuarto de los diputados del bloque peronista (Levitsky, 2003: 134).

Tras el colapso del gobierno radical de Raúl Alfonsín, triunfaría, en 1989, el candidato peronista, Carlos Menem, con un discurso netamente dirigido al mundo del trabajo bajo las consignas «Revolución Productiva» y «Salariazo». Los sectores obreros votaron mayoritariamente por Menem, que cosechó el 60 \% de los votos de los obreros capacitados y el $74 \%$ de los votos de los obreros no capacitados (Catterberg y Braun, 1989). Tal vez, esta fuera la última elección en la que el peronismo apelaría al sindicalismo como columna electoral cardinal. A pesar de la identificación de Menem con las banderas clásicas del peronismo, una vez en el gobierno, giró hacia políticas de corte liberal que impondrían altos costos sociales. En la década de 1990 cristaliza un proceso de reconfiguración de la estructura social del que emergen nuevos electores y actores políticos.

Si hasta la década de 1970 se podía seguir afirmando que la Argentina era una sociedad salarial distintiva en América Latina, a partir de la crisis de la deuda y la reforma de mercado de 1990, ya no se podrá sostener lo mismo. Como lo muestra el Gráfico 1, al inicio del gobierno de Menem, la tasa de desocupación, que venía creciendo desde 1985, alcanza un $7 \%$ para llegar a un exorbitante $20 \%$ hacia mediados de su gestión. Desde entonces hasta la actualidad, la tasa de desempleo, que toca un techo del $22 \%$ en 2002 y un piso del $7 \%$ en 2015, se mantuvo en promedio en torno al $10 \%$ anual. En el Gráfico 2, se observa un proceso similar en la tasa de no registración. Hacia mediados de los 90 superará a un tercio de la Población Económicamente Activa (PEA) para ya nunca bajar de ese porcentaje, alcanzando en 2003 a casi el $50 \%$. Las medidas económicas que, como consecuencia de la convertibilidad, dotaban de ingresos relativamente altos a los asalariados formales, dejaban afuera del sistema a un creciente número de desocupados y trabajadores informales, conformándose un mercado de trabajo dual. Despedidos que con sus indemnizaciones abrieron quioscos o brindaron servicios de remis, jefes y jefas de hogar que encontraron en los planes sociales su principal fuente de ingreso, microemprendedores populares, vendedores ambulantes y feriantes, trapitos, cartoneros y una nueva población en situación de calle fueron solo algunos de los trabajadores que sufrieron en carne propia el progresivo deterioro de las condiciones materiales de vida y se integraron al paisaje urbano. En la Marcha Federal de 1994 se expresaban los variados reclamos de estos nuevos actores frente a la reforma de mercado. 


\section{Gráfico 1}

Tasa de Desocupación (1974-2018) en \%

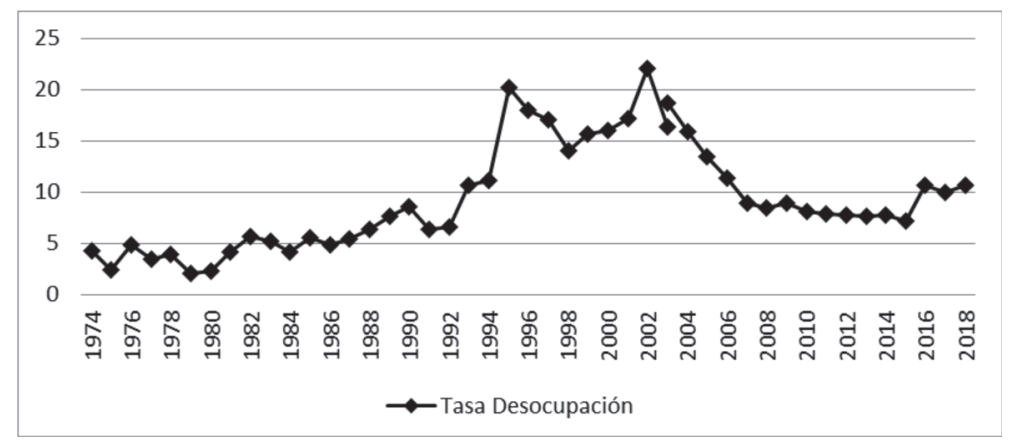

Fuente: elaboración propia en base a EPH (GBA).

\section{Gráfico 2}

Tasa de no registración (1975-2018), en \%

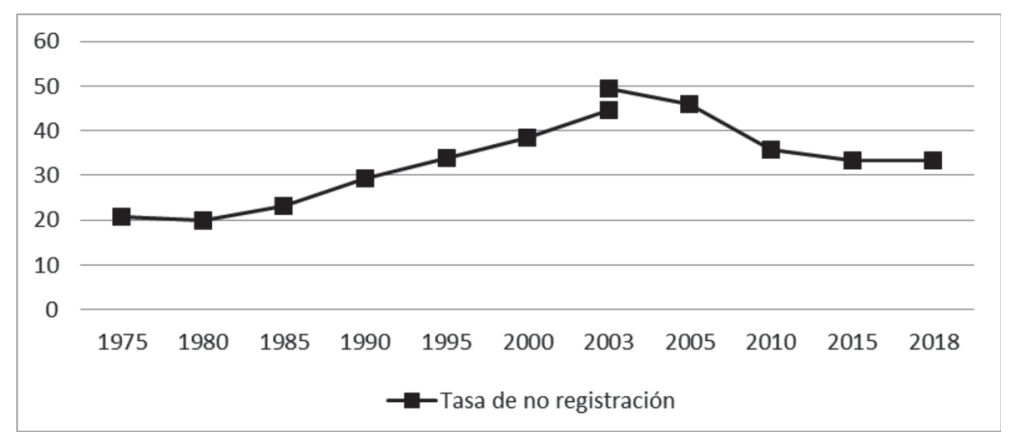

Fuente: elaboración propia en base a EPH (GBA)

Justamente, reconociendo esta realidad, los dos candidatos principales en la campaña electoral de 1995, Carlos Menem y José Octavio Bordón, peronistas ambos, centraron sus campañas en el desafío de crear fuentes de trabajo dignas. Los informales y desempleados constituyen desde ese entonces un importante destinatario de las campañas electorales. Las reformas de mercado, implementadas paradójicamente por un presidente peronista, y la consecuente crisis de 2001 quebraron definitivamente la estructura social heredada del peronismo. El proceso de deterioro de las condiciones materiales de los más pobres, que llevaba ya varias décadas, se ace- 
leró y fragmentó la relativa homogeneidad de la clase trabajadora que había distinguido a la Argentina del resto de los países de América Latina.

En el marco de desocupación e informalidad laboral que se dan las primeras movilizaciones de desocupados en Cutral Co-Plaza Huincul (1996) y Tartagal y General Mosconi (1997). El gobierno, para pacificar y evitar mayor conflicto social, respondió a estas con la concesión de planes de trabajo. En Cutral Co-Plaza Huincul se concedieron 1.500 Planes Trabajar, mientras que en Tartagal y General Mosconi 3.000. Este desenlace provocó que a partir de entonces los movimientos de desocupados se articularan con el objetivo preciso de extraerle planes sociales a un gobierno que quería evitar la escalada del conflicto social. En el Conurbano bonaerense el axioma «planes o corte de ruta» se impuso como norma de negociación y los movimientos sociales multiplicaron los piquetes como forma de protesta. Un improbable nuevo actor social y político había emergido. Sin lazos laborales que unifiquen sus intereses e identidad y sin sindicatos que los representen, los trabajadores informales y desocupados eran, hasta entonces, una rara fuente de conflicto social. Sin embargo, los planes sociales actuaron como catalizador de una creciente acción colectiva; entre 1997 y 2003, el país experimentó un promedio de 137 acciones de protesta por año por parte de los movimientos de desocupados y trabajadores informales (Garay, 2007; Franceschelli y Ronconi, 2009).

El Plan Trabajar, destinado a desempleados, arrancó en 1996 con 62.000 beneficiarios que se duplicarían al año siguiente. Se sucedieron luego una gran cantidad de programas, de los cuales el más masivo fue el Plan Jefes y Jefas de Hogar (PJJH). Implementado en 2002 para aminorar los estragos que causaban los efectos de la colosal crisis económica de 2001, alcanzó alrededor de 2.500.000 beneficiarios en 2003 (Ronconi, 2009). Desde entonces hasta la actualidad, los planes de empleo, que han ido variando en cantidad de beneficiarios pero que, en promedio, no han bajado en los últimos 10 años de los 400.000, fueron una de las principales fuentes de ingreso para muchos desocupados y trabajadores informales.

La fragmentación social le quitó a los sindicatos el monopolio de la representación de los trabajadores. Cuando los trabajadores informales y desempleados, que forman el núcleo duro del $30 \%$ de los pobres en la Argentina, logran articular y expresar sus demandas es a través de diversos movimientos y organizaciones sociales. En cambio, los trabajadores formales, que son aproximadamente el $40 \%$ de la fuerza de trabajo ocupada, continúan siendo principalmente representados por los sindicatos. También en el Congreso se vio reflejada esta pérdida de poder relativo del sindicalismo, allí quedó perimida la ley de tercio y, desde 2003, en las sucesivas elecciones legislativas fueron elegidos solo uno o dos candidatos de proce- 
dencia sindical, mientras que ingresaron tres o cuatro provenientes de organizaciones sociales. Aunque los reclamos de ambos sectores incluyen la justicia social, los movimientos sociales la expresan como necesidad de obtener asistencia social del estado, mientras que los sindicatos reclaman por el salario real, las obras sociales y, en forma creciente en la última década, contra el impuesto a las ganancias. Los bifurcados reclamos expresan las diferencias que existen entre los trabajadores y ponen de manifiesto la fragmentación social de la base electoral del peronismo.

Con la reactivación económica posterior a la crisis de 2001, el sindicalismo recuperaría el centro de la escena. Si desde 2003 más del $50 \%$ de los conflictos fue liderado por movimientos de desocupados, a partir de 2005 más del $75 \%$ lo estaría en manos sindicales (Etchemendy y Collier, 2007). Sin embargo, el resurgimiento sindical, con la consecuente retracción de los movimientos, no puede interpretarse como el fin del mercado laboral dual que había llegado para quedarse. Bien describe el escenario actual el líder del Movimiento Evita, Emilio Pérsico: «La clase trabajadora está dividida en tres pedazos: la crema, la leche y el agua. La crema en una sociedad como la nuestra es hasta el $20 \%$ de los trabajadores, trabajadores integrados, los trabajadores reconvertidos, dicen ellos, ¿no? Son estos trabajadores que consumen, que compran dólares. Después está otro sector que sí es bastante más grande, que es la leche, que sí es el sector de trabajadores no reconvertidos. Muchos de la UOM, de textiles, no reconvertidos. Finalmente están los trabajadores de la economía popular. Ejemplos: fábricas recuperadas, cooperativas, los cartoneros... Un trabajador de los primeros cobra por encima de las veinte lucas, los otros estarán de veinte a ocho, a siete, o a cinco, y después una gran masa de la economía popular, de trabajadores que se autoinventaron el trabajo. Que son improductivos en términos capitalistas, que tienen otro tipo de producción que es difícil de comprender para el capitalismo». Interrogado sobre cómo ve la cúpula sindical a los trabajadores de la economía popular, aclara: «Pienso que un sector sindical importante los mira impertérritos: son el afuera. Nada del orden sindical que quieren preservar se altera por ellos» (Abal Medina, 2016).

La formalidad laboral continuará siendo definitoria de accesos a servicios fundamentales. Los trabajadores formales o con ingresos altos acceden a la cobertura médica de obras sociales sindicales o de prepagas privadas, mientras que los informales o desocupados acuden a los hospitales públicos que han ido sufriendo, en general, un constante deterioro. Los sectores obreros medios tienen mayores posibilidades de elegir educación privada para sus hijos, mientras que los informales dependen de la suerte de la escuela pública. La tasa de graduación en las escuelas secundarias privadas es casi el doble que el de las escuelas estatales. «De cada 100 niños que 
ingresaron a primer grado en una escuela privada en nuestro país en 2002, 70 de ellos lograron la graduación secundaria en el 2013. Pero de cada 100 que ingresaron a primer grado estatal en 2002, en el 2013 concluyeron la secundaria apenas 27» (Guadagni, 2015: 11).

De hecho, durante el gobierno de Néstor Kirchner y luego el de Cristina Fernández de Kirchner, existirán políticas claramente diferenciadas para ambos sectores. Por un lado, los sectores formales vieron un marcado incremento de la relevancia de las negociaciones colectivas y una clara recomposición del salario real. Por otro, los sectores informales fueron beneficiarios de una monumental política de transferencia de ingresos. En 2005, Cristina Kirchner firmó el decreto de moratoria previsional que llevaría a que los jubilados y pensionados pasaran de 3 millones a fin de ese año a casi 6 millones en 2012. Desde entonces hasta la actualidad, el $45 \%$ de los jubilados accedieron a la prestación a través de moratoria. A la moratoria previsional se le sumaron las Pensiones No Contributivas, que aumentaron $180 \%$ entre 2005 y 2012, y alcanzaron casi el millón y medio de prestaciones hacia el fin del kirchnerismo (Ministerio de Economía y Finanzas Públicas, 2013). En 2009, Cristina Kirchner lanzó por decreto la Asignación Universal por Hijo (AUH) que, a los dos años, llegó a más de 3,5 millones de niños en casi 2 millones de hogares. A estas grandes transferencias de ingresos hacia los sectores desocupados e informales se sumaron programas como el Argentina Trabaja, que alcanzó prontamente los 250.000 beneficiarios, y otros planes y seguros de desempleo manejados desde el Ministerio de Trabajo. Gracias a esta generosa política de ingresos hacia los sectores más vulnerables y a la recomposición del salario real, los obreros formales y los informales y desocupados se volcaron mayoritariamente a favor de Cristina Kirchner.

Que Cristina Kirchner hubiera conseguido el apoyo de ambos sectores no significa que estos tuvieran los mismos intereses. Siempre existieron tensiones entre los movimientos sociales y la CGT. Paula Abal Medina (2016) describe bien las diferencias entre las columnas sindicales y las columnas de las organizaciones sociales en los actos kirchneristas. Estas tensiones crecieron y fueron particularmente notorias con la discusión por el pago de ganancias en que se enfrascó el sindicalismo y la ruptura de líder sindical Hugo Moyano con Cristina Kirchner. Si bien en los últimos años, los representantes de Barrios de Pie, la Corriente Clasista y Combativa (CCC) y la Confederación de Trabajadores de la Economía Popular (CTEP) buscaron integrarse con la CGT, no han logrado reconocimiento alguno hasta el momento. Juan Grabois, de la CTEP, decía al respecto: «Nosotros siempre sostuvimos que este sindicalismo excluyó a los trabajadores de la economía popular, y ese es un problema que hay que solucionar» (Gestión Sindical, 2018). 
De hecho, acompañando la fragmentación de la condición laboral, la percepción que las personas tienen sobre los planes sociales se convertiría en una divisoria de aguas fundamental en la «grieta». Un tercio de los hogares argentinos recibe ingresos por planes sociales (Bonfiglio y Vera, 2018) . $^{3}$ Para estos hogares, en general con jefes y jefas desempleados o con trabajos informales, esos ingresos son primordiales dentro del conjunto de sus estrategias de sobrevivencia, por lo que sectores movilizados reclaman por la persistencia y el incremento de los mismos. Por otra parte, quienes no los reciben, en general asalariados formales, tienden a tener una mirada negativa sobre los planes sociales, dado que perciben que ellos trabajan formalmente y pagan impuestos para sostener el gasto social. No es raro escucharlos decir que, con su aporte, «mantienen vagos». Sostenemos entonces que los planes sociales constituyen un clivaje social con importantes consecuencias electorales que afectan más al peronismo que al resto de los partidos. El candidato peronista enfrenta el desafío de satisfacer simultáneamente a votantes que viven de los planes y a votantes que ven a los planes como parte del problema del país.

La fragmentación social también se expresa territorialmente en el hábitat de los votantes. El país tiene $30 \%$ de pobres (13 millones de personas) y $6 \%$ de indigentes (2,5 millones de personas). A nivel nacional, la riqueza se concentra en la región más productiva de la pampa húmeda mientras que la pobreza en la zona norte y oeste del país. Hacia el interior de cada provincia los centros urbanos tienden a tener mayor riqueza que las zonas periféricas, pero, a su vez, las grandes ciudades suelen estar rodeadas de conurbanos pobres. Claro ejemplo de esto es la Ciudad de Buenos Aires que, siendo la única jurisdicción con solo un digito de pobreza, está rodeada de 33 municipios que conforman el Conurbano bonaerense y tienen un índice de pobreza cercano al $36 \%$. Dentro de cada uno de estos 33 municipios, la pobreza también tiene una clara distribución territorial; mientras en sus cabeceras se concentran los estratos medios y altos, a medida que se aleja de ellas y del trazado ferroviario, se encuentran los sectores más bajos.

La fragmentación social en el hábitat es también palpable en el aumento de la población en villas y asentamientos. Si bien los datos fidedignos y comparables escasean, el censo realizado en 2017 por el Registro Nacional de Barrios Populares (RENABAP) permite algunas conjeturas. Si comparamos la cantidad de villas en el Conurbano bonaerense según el censo 2001 y las actuales cifras provistas por el RENABAP, el número se triplicó en 16 años. Según el censo 2001 eran menos de 400, según un estudio de la Uni-

Entendemos aquí «plan social» en un sentido amplio, que abarca Asignación Universal por Hijo, cooperativas del programa Argentina Trabaja, pensiones no contributivas, jubilaciones por moratoria, planes de desempleo, etc. 
versidad de General Sarmiento para 2006 eran 796 y para 2017, según RENABAP, cerca de 1.200 (Cravino, 2009). De acuerdo a RENABAP, en la actualidad existen 4.228 villas y asentamientos en todo el país, que concentrarían 3,5 millones de personas. Sumadas, cubren un área equivalente a dos superficies de la Ciudad de Buenos Aires $\left(416 \mathrm{~km}^{2}\right)$. En estas villas y asentamientos el acceso a servicios y bienes públicos es claramente deficiente e inferior al que se tiene en barrios formales.

La película que hemos descripto es la de la creciente fragmentación de la clase obrera y el deterioro de las condiciones materiales de vida de los más pobres. Nuestra hipótesis es que el peronismo sufre electoralmente esta progresiva heterogeneidad. No es difícil comprobarlo en las historias cotidianas de trabajadores de nuestro país. Por ejemplo, Fidelina es empleada formal en un hotel céntrico donde realiza tareas de limpieza. Vive en el barrio de los italianos en Lanús y está agradecida con el intendente porque incorporó iluminación LED en las calles, pero se queja de la inseguridad y de que su cuñada, Maricel, se haya jubilado sin haber trabajado nunca. Sostiene que «los que trabajamos mantenemos vagos». Maricel efectivamente entró en la moratoria provisional de 2015, vive en una villa llamada La Fe y se queja de que, con la inflación, la jubilación no le alcanza para nada. Tanto Maricel como Fidelina provienen de hogares peronistas de trabajadores ferroviarios, pero hoy Maricel se siente representada por Unidad Ciudadana y Fidelina por Cambiemos. Héctor vive en el centro de Avellaneda y es dueño de un taxi. Se queja de su primo Rubén, al que considera un vago porque es «un planero» que cobra el Argentina Trabaja. «Tendría que llamarse Argentina Descansa», dice. Cuando Rubén participa en el piquete que corta el Puente Pueyrredón, Héctor quiere que la policía «lo cague a palos hasta que vaya a laburar». En 2015, Héctor votó por Sergio Massa y Rubén lo hizo por Daniel Scioli. Carlitos es un cartonero que vive en una villa del municipio de Moreno. Está agradecido con el puntero de la villa porque le dio unas chapas para hacer el techo de su casa y consiguió que la municipalidad volcara cascotes sobre la calle para facilitarle el acceso con el carro. Contrasta con la preocupación de José, que es panadero y vive a pocas cuadras de Carlitos, y se queja de que no tiene cloacas ni asfalto y de que la escuela a la que asisten sus hijos es de muy mala calidad. Carlitos cree que solo Cristina Kirchner puede mejorar su situación, mientras que José cree que Juan Manuel Urtubey sería un buen presidente.

Estas historias con las que nos hemos topado en el Conurbano bonaerense ilustran la fragmentación de la otrora más homogénea base del voto peronista. No significa esto que no exista político capaz de representar a la vez a obreros formales y desocupados, a asalariados y beneficiarios de planes o a habitantes de villas y asentamientos y de barrios formales. Cristina 
Kirchner consiguió el apoyo de estos sectores diversos en 2007 y 2011. Es posible representar intereses diversos e incluso, a veces, hasta a grupos antagónicos, pero es más difícil que representar a un grupo homogéneo en sus intereses. Cuando un candidato intenta representar distintos sectores con intereses no coincidentes, abre la oportunidad a que otro candidato focalice sus promesas en uno de los sectores y le arrebate una porción de votantes. De hecho, como se puede ver en el Tabla 1, desde 2003 hasta la actualidad, el peronismo siempre ha tenido más de un candidato en las elecciones presidenciales. Nuestra hipótesis es que en 2015 y 2017, los candidatos peronistas expresaron esa grieta en la base electoral del peronismo: los sectores más pobres votaron al Peronismo K, Frente por la Victoria - Unidad Ciudadana, y los sectores medio bajo votaron parcialmente por el Peronismo no Kirchnerista o, incluso, por Cambiemos. El siguiente punto busca ofrecer evidencia sobre el caso.

Tabla 1

Porcentaje de votos de candidatos peronistas a la presidencia 2003-2015

\begin{tabular}{|c|c|c|c|c|}
\hline Año & Candidato & Partido & $\%$ & $\%$ Acumulado \\
\hline \multirow{3}{*}{2003} & Carlos S. Menem & Alianza Frente por la Libertad & $24,45 \%$ & \multirow{3}{*}{$60,80 \%$} \\
\hline & Néstor Kirchner & Alianza Frente para la Victoria & $22,24 \%$ & \\
\hline & Adolfo Rodríguez Saá & Frente Movimiento Popular & $14,11 \%$ & \\
\hline \multirow{2}{*}{2007} & Cristina Kirchner & Frente para la Victoria & $45,28 \%$ & \multirow{2}{*}{$52,92 \%$} \\
\hline & Alberto Rodríguez Saá & Frente Justicia, Unión y Libertad & $7,64 \%$ & \\
\hline \multirow{3}{*}{2011} & Cristina Kirchner & Frente para la Victoria & $54,11 \%$ & \multirow{3}{*}{$67,93 \%$} \\
\hline & Alberto Rodríguez Saá & Alianza Compromiso Federal & $7,96 \%$ & \\
\hline & Eduardo Duhalde & Alianza Frente Popular & $5,86 \%$ & \\
\hline \multirow{3}{*}{2015} & Daniel Scioli & Frente para la Victoria & $37,08 \%$ & \multirow{3}{*}{$60,11 \%$} \\
\hline & Sergio Massa & Unidos por una Nueva Alternativa & $21,39 \%$ & \\
\hline & Adolfo Rodríguez Saá & Alianza Compromiso Federal & $1,64 \%$ & \\
\hline
\end{tabular}

Fuente: elaboración propia en base a datos de la Dirección Nacional Electoral.

\section{Datos y evidencia empírica}

Testear nuestra hipótesis requeriría de una muestra representativa de los votantes de los sectores que conforman la base electoral histórica del peronismo. Esto implicaría una base que incluya cómo votaron los sectores de ingresos y educación medios y bajos, los beneficiarios de planes, los habitantes en villas y los trabajadores formales, informales y desocupados. La muestra debiera tener información sobre todos estos aspectos y la cantidad de observaciones suficientes para tener poder estadístico y testear nuestra 
hipótesis. Lamentablemente no existe en Argentina ninguna encuesta que cumpla con estos requisititos. Es necesario, entonces, reconocer que la información disponible impone límites a nuestro estudio. Las muestras que elaboran las consultoras suelen excluir la población que vive en villas miseria por motivos de acceso y seguridad, y la mayoría de las veces no distinguen entre trabajadores formales e informales por la complejidad de las preguntas para obtener esta información. Asimismo, la cantidad de personas encuestadas suele ser demasiado baja para testear con poder estadístico hipótesis referidas a ciertas sub-poblaciones, como por ejemplo, la distribución de preferencias electorales entre los beneficiarios de planes sociales. Reconocidas las limitaciones existentes, para subsanar la falta de una muestra ideal se adoptó una estrategia múltiple. Primero, realizamos un análisis econométrico a nivel votante utilizando la acumulación de cinco bases de datos y, segundo, realizamos un análisis espacial de la distribución del voto comparando el porcentaje de hogares en villas y asentamientos en los 1083 circuitos electorales de la Provincia de Buenos Aires.

\subsection{Evidencia con bases de datos}

Partimos de utilizar los datos ya existentes del APES (Argentine Panel Election Study). A esta encuesta agregamos bases de Isonomía Consultores y de M y R Asociados. Estas consultoras aceptaron agregar preguntas a sus cuestionarios, lo que nos permitió recabar información relevante a nuestra hipótesis. A su vez, una versión reducida de la encuesta realizada por Isonomía fue llevada a cabo por el equipo del CIAS en villas y asentamientos para incorporar esta población que es usualmente ignorada en las encuestas. Adicionalmente, el CIAS colaboró en el diseño de una encuesta en la Municipalidad de Lanús, lo que permitió agregar las preguntas pertinentes a este estudio. Finalmente, se creó una base total de datos que resulta de apilar las cinco muestras mencionadas ${ }^{4}$.

La Tabla 2 presenta estadísticas básicas para la base total y para cada uno de sus componentes. Dada la hipótesis a testear, y asumiendo que la base histórica del peronismo son los sectores de nivel educativo medio y bajo, el análisis se circunscribe a la población con nivel educativo de hasta con secundaria completa. La base total contiene un total de 3.670 personas, de las cuales el $6 \%$ habita en villas miserias, el $26 \%$ es beneficiario de un plan social, y solo el $45 \%$ de los ocupados tiene empleo formal. Si bien estos valores tienen alguna diferencia con la población electoral argentina, son

El Apéndice explica detalladamente las características de cada una de las cinco muestras utilizadas. 
más cercanos que cualquiera de las muestras individuales tomadas por separado $^{5}$.

\section{Tabla 2}

Estadísticas descriptivas

\begin{tabular}{|l|r|r|r|r|r|r|}
\hline Variable & \multicolumn{1}{|c|}{ APES } & ISONOMIA & \multicolumn{1}{c|}{ MyR } & \multicolumn{1}{c|}{ CIAS } & Lanús & Base Total \\
\hline Recibe plan social & $32 \%$ & $13 \%$ & $13 \%$ & $52 \%$ & $26 \%$ & $\mathbf{2 6 \%}$ \\
\hline Trabajador formal & $43 \%$ & $52 \%$ & $54 \%$ & $24 \%$ & $34 \%$ & $\mathbf{4 5 \%}$ \\
\hline Habita villa miseria & $0 \%$ & $0 \%$ & $0 \%$ & $100 \%$ & $16 \%$ & $\mathbf{6 \%}$ \\
\hline AMBA & $45 \%$ & $60 \%$ & $66 \%$ & $100 \%$ & $100 \%$ & $\mathbf{6 3 \%}$ \\
\hline Hombre & $47 \%$ & $47 \%$ & $42 \%$ & $45 \%$ & $44 \%$ & $\mathbf{4 5 \%}$ \\
\hline Edad & 43.7 & 43.0 & 54.1 & 39.4 & 44.2 & $\mathbf{4 6 . 8}$ \\
\hline
\end{tabular}

Fuente: elaboración propia en base a encuestas citadas.

La hipótesis central es que la otrora unificada base electoral del peronismo se encuentra actualmente fragmentada y que dicha fragmentación se expresa en diferentes preferencias electorales. Aquí testeamos la fragmentación social y sus consecuencias electorales sobre el peronismo en tres dimensiones fundamentales: laboral, fiscal y territorial. La fragmentación laboral es medida por la formalidad o informalidad en las condiciones de trabajo, la fiscal por si el votante percibe algún ingreso de planes sociales o no y la territorial por si el votante vive en villa o asentamiento o no. Obviamente se trata de medidas parciales de la fragmentación social que se superponen pero cada una posee suficiente riqueza por sí misma para justificar su utilización por separado.

Los gráficos 1 al 3 ilustran la hipótesis central del documento. El gráfico la muestra que el 73,8 \% de las personas que habitan en villas miserias o asentamientos reportan haber votado al PJ K, mientras que dicha figura alcanza al 46,8\% entre los que no habitan en villa. Una marcada preferencia por el PJ K en el segmento más vulnerable. Debido a que la muestra se circunscribe a personas que votaron al PJ K, al Peronismo no K, o a Cambiemos, los resultados del gráfico indican a su vez que solamente el 26,2 \% de las personas que habitan en villas miserias reportan haber votado al Peronismo no $\mathrm{K}$ o a Cambiemos, mientras que entre los que no viven en las villas el apoyo a estos fue del doble (53,2\%). El gráfico 2a muestra que 67,8\% de los que reciben planes sociales vota por el FPV, mientras que entre los que no reciben algún plan social se limita al 45,4\%. Finalmente, el gráfico 3a ilustra

Como el 97 \% de la muestra declara haber votado por Cambiemos, Peronismo kirchnerista o Peronismo no kirchnerista nos circunscribimos a dicha población. 
el mayor apoyo que recibe el PJ K entre los trabajadores informales $(52,1 \%)$ respecto a los formales $(40,2 \%)$. En los tres casos las diferencias son estadísticamente significativas al $99 \%$. Es decir, el segmento socialmente más vulnerable de la antigua base electoral del Peronismo (i.e., informales, beneficiarios de planes y habitantes de villas y asentamientos), muestra preferencias electorales marcadamente diferentes respecto a segmentos medios (i.e., formales, que no perciben planes sociales y no habitan en asentamientos); mientras que los primeros se vuelcan mayoritariamente por el FPV, los segundos lo hacen por candidatos del Peronismo no K o Cambiemos.

\section{Gráfico 1a.}

Porcentaje que vota al FPV

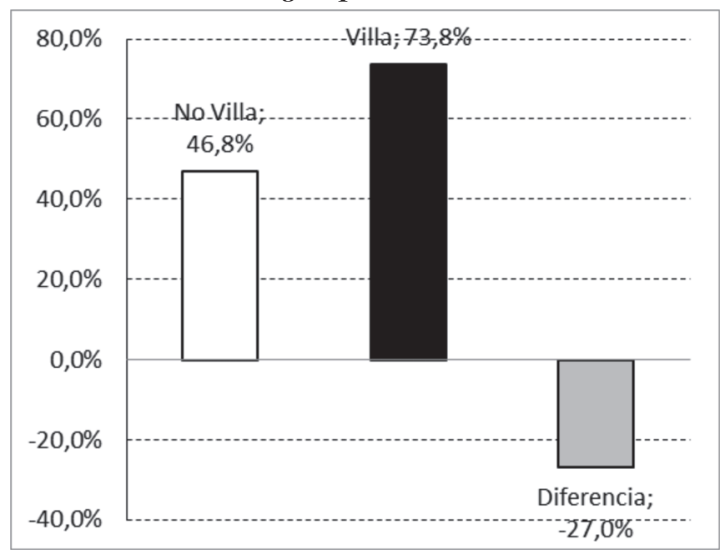

Gráfico 2a.

Porcentaje que vota al FPV

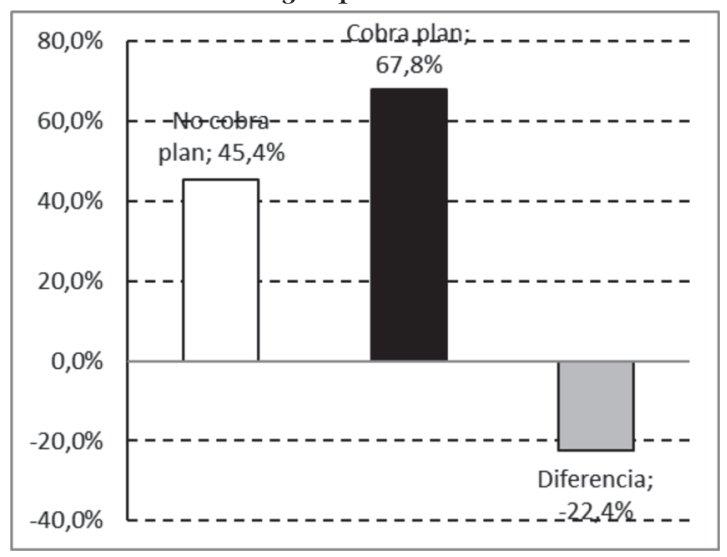


Revista SAAP $\cdot$ Vol. 13, № 1

\section{Gráfico 3a.}

Porcentaje que vota al FPV

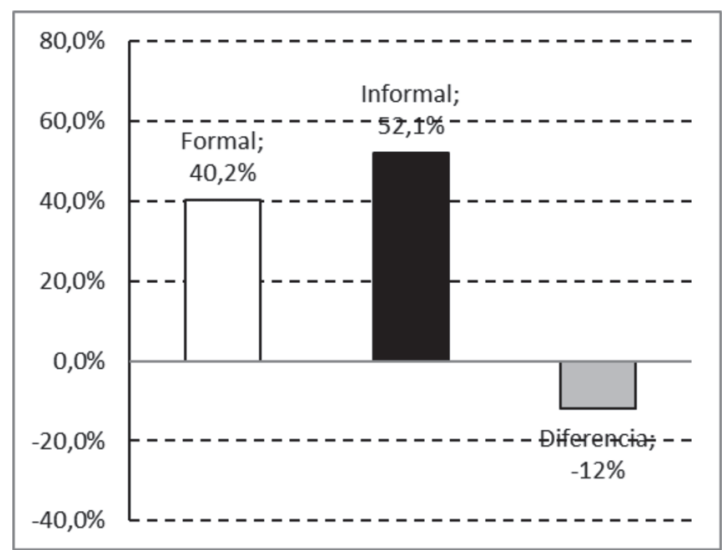

Gráfico $1 b$.

Porcentaje que vota a Cambiemos

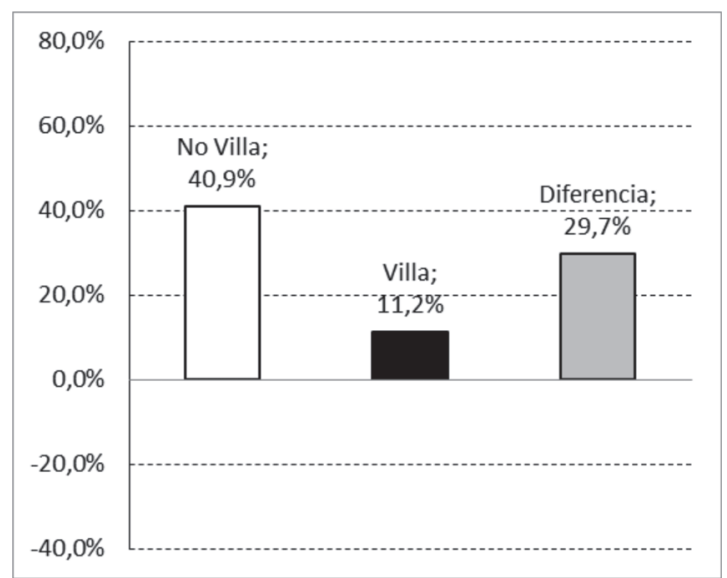

Los gráficos $1 \mathrm{~b}$ a $3 \mathrm{~b}$ muestran los votos de Cambiemos, y es interesante notar como los datos reflejan la famosa «grieta» argentina al invertir las proporciones con respecto al FPV. Si los habitantes de las villas y asentamientos tienden a votar 27 puntos porcentuales (p.p.) más al FPV que los que no habitan en villas y asentamientos, lo contrario ocurre con Cambiemos; solo el $11,2 \%$ de los habitantes en villas lo vota mientras que casi el $41 \%$ de los que no viven en villa lo hace. Lo mismo sucede con los planes sociales, el $42 \%$ de los que no lo reciben vota a Cambiemos frente al 20,9\% de los que sí perciben planes. Y los trabajadores formales votan un 10 p.p. más a Cambiemos que los 
Rodrigo Zarazaga S.J.

informales. Estas diferencias son estadísticamente significativas al $99 \%$. En cuanto clivaje social estructural, Cambiemos es el negativo del FPV.

\section{Gráfico 2b.}

Porcentaje que vota a Cambiemos

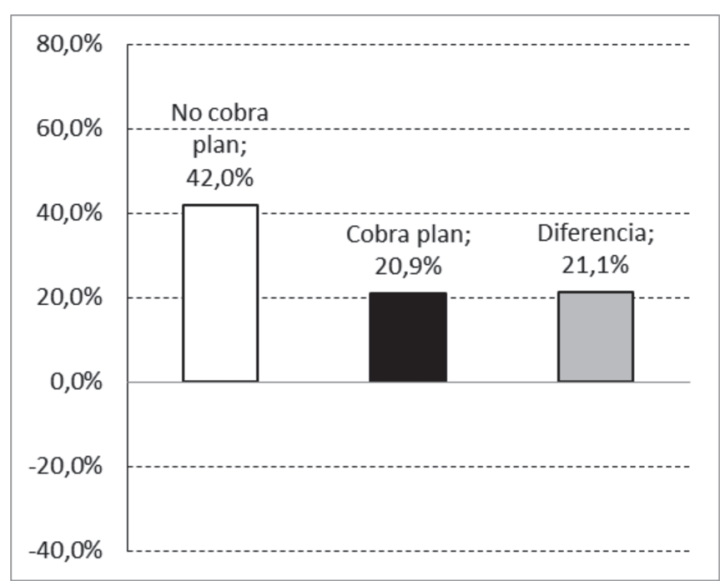

Gráfico 3b.

Porcentaje que vota a Cambiemos

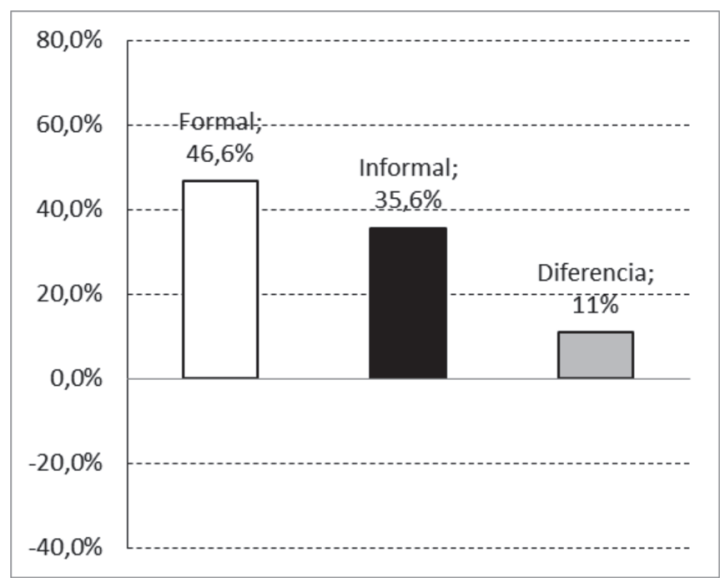

No menos interesante son los datos para el PJ no K en los gráficos 1c a 3c. Si bien no se puede afirmar, como en el caso de Cambiemos, que sus votantes sean el negativo estructural del FPV, sí se observa una base electo- 
ral distinta. Mientras al FPV lo vota un $63 \%$ más la población villa que la en No villa, en el PJ no K la diferencia es menor al 3 p.p. y no significativa. En este aspecto, los sectores que declaran votar por el PJ no K serían menos marginales que los que lo hacen por el PJ K. Lo mismo ocurre con los planes sociales. Si quienes lo reciben declaran votar más por el PJ K que quienes no los reciben, lo contrario ocurre entre los votantes del PJ no K; los que no reciben lo votan 1,2 p.p. más que quienes lo reciben. Aunque por su pequeño tamaño esta diferencia no es estadísticamente significativa, y debe interpretarse con cautela, la evidencia pareciera señalar de todos modos un clivaje dentro del peronismo en torno a los planes sociales. Exactamente lo mismo ocurre en torno a la formalidad laboral. Mientras los informales tienden claramente a votar más al PJ K, esto no ocurre con el PJ no K. La evidencia, con todas las limitaciones del caso, pareciera indicar que la grieta no solo divide la base electoral entre FPV y Cambiemos sino también dentro del peronismo entre PJ K y PJ no K.

Gráfico 1c.

Porcentaje que vota al PJ no K

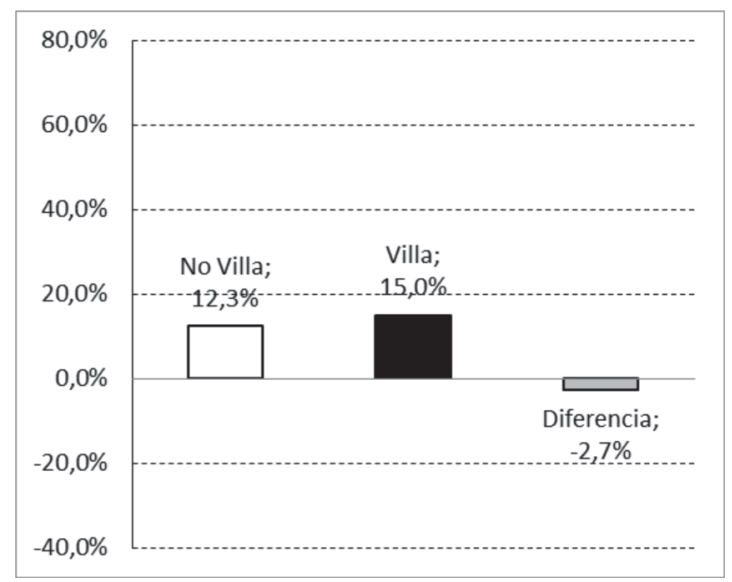


Rodrigo Zarazaga S.J.

Gráfico 2c.

Porcentaje que vota al PJ no K

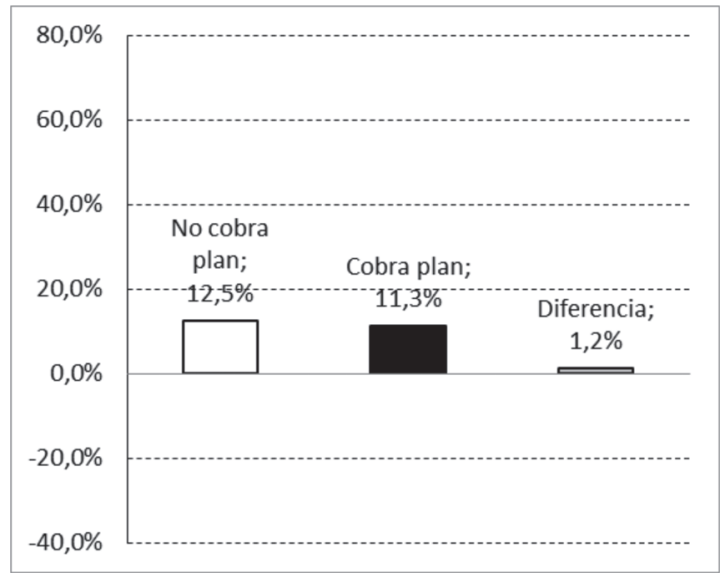

Gráfico 3c.

Porcentaje que vota al PJ no K

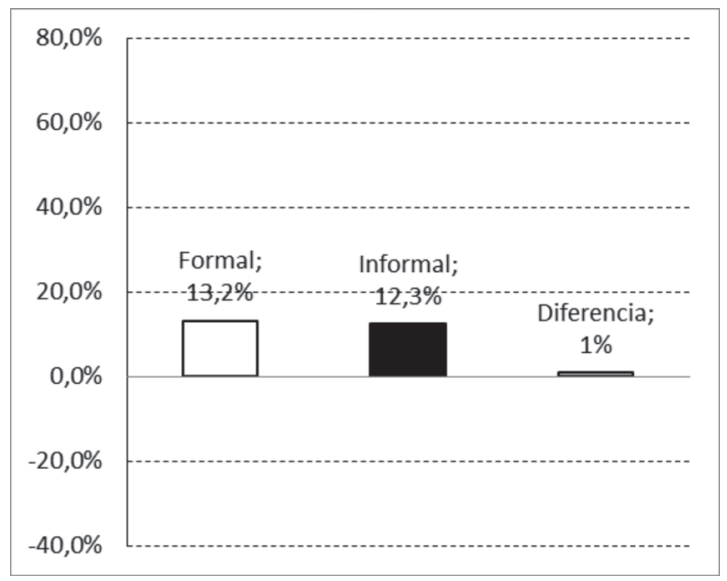

Si bien los gráficos confirman nuestra hipótesis pueden sufrir problemas de variable omitida. Es por eso que se complementan con la siguiente especificación econométrica:

Voto $_{i}=\alpha+\beta$ Dimension $_{i}+\boldsymbol{X}_{i}+\varepsilon_{i} ;$

donde Vto $_{i}$ es igual a 1 si la persona $i$ reporta haber votado al FPV en la última elección y 0 si reporta haber votado a Cambiemos o a un candidato 
del Peronismo no K. Como se mencionó arriba la muestra se restringe a la población con nivel educativo de secundaria completa o menos. Dimensión se refiere a los tres ejes sociales enfatizados en este documento: formalidadinformalidad laboral; habita o no en villa miseria; beneficiario o no de plan social; $\boldsymbol{X}$ es un vector de variables de control que incluyen el sexo, la edad, y la región donde vive el votante ${ }^{6}$. Se estima con un modelo probit con errores estándares robustos. La Tabla 3 reporta los efectos marginales $\mathrm{dF} / \mathrm{dx}$.

\section{Tabla 3}

Efectos de vulnerabilidad social sobre preferencias electorales

\begin{tabular}{|c|c|c|c|}
\hline \multicolumn{4}{|c|}{$\begin{array}{l}\text { Variable dependiente }=\text { Voto a FPV }=1 \text {; Voto a PJ no K o } \\
\text { Cambiemos }=0\end{array}$} \\
\hline & $(1)$ & (2) & (3) \\
\hline \multirow[t]{2}{*}{ Villa miseria } & $0.223 * * *$ & - & - \\
\hline & $(0.034)$ & & \\
\hline \multirow[t]{2}{*}{ Plan social } & - & $0.197 * * *$ & - \\
\hline & & $(0.021)$ & \\
\hline \multirow[t]{2}{*}{ Trabajador informal } & - & - & $0.111 * * *$ \\
\hline & & & $(0.023)$ \\
\hline \multirow[t]{2}{*}{ Sexo $($ Hombre $=1)$} & -0.009 & 0.014 & $0.039 *$ \\
\hline & $(0.017)$ & $(0.019)$ & $(0.023)$ \\
\hline \multirow[t]{2}{*}{ Edad } & $-0.004 * * *$ & $-0.003 * * *$ & $-0.005^{* * *}$ \\
\hline & $(0.001)$ & $(0.001)$ & $(0.001)$ \\
\hline Indicadores regionales & $\mathrm{Si}$ & $\mathrm{Si}$ & $\mathrm{Si}$ \\
\hline Observaciones & 3670 & 3125 & 1929 \\
\hline
\end{tabular}

Fuente: elaboración propia en base a encuestas citadas.

Nota: Modelos probit con errores estándares robustos. Se reportan los efectos marginales. Estadísticamente significativos al $10 \% *, 5 \% * *$, y $1 \%$ ***.

En las columnas se introducen por separado las tres dimensiones sociales que enfatiza este documento, y encontramos que las tres son muy útiles para comprender las preferencias electorales de los votantes aun luego de controlar por un conjunto de variables socio-demográficas. Nótese que la magnitud del coeficiente se reduce en los tres casos (por ejemplo, en el gráfico 1 se observa que la diferencia en el voto al FPV entre los que habitan en villa respecto a los que no, es de 27 puntos porcentuales, pero al controlar por otras variables se reduce a 22 puntos porcentuales tal como indica la

6 Las regiones son AMBA, Pampeana, Cuyo, NEA, NOA, Patagonia. 
columna 1 de la tabla 2); pero los resultados siguen siendo política y estadísticamente significativos.

Una duda que puede surgirle al lector es la robustez de los resultados frente al análisis por separado de cada muestra. La encuesta de Lanús es la única que contiene información sobre las tres dimensiones, y por ende permite realizar el testeo completo de las tres hipótesis. Obviamente tiene el problema de que los resultados solo se refieren a un municipio de todo el país, pero históricamente Lanús es un termómetro representativo de lo que ocurre social y electoralmente en el conurbano. En el Apéndice se presenta el análisis utilizando solo los datos de la encuesta de Lanús, y cualitativamente se observan todos los mismos fenómenos arriba resaltados. La fragmentación laboral, espacial y fiscal se traduce en diferentes preferencias electorales dentro de la base electoral del peronismo.

\subsection{Evidencia Espacial de la grieta}

Otra prueba adicional que tiende a confirmar nuestra hipótesis proviene de un análisis espacial del voto. El análisis a nivel circuito de los resultados electorales oficiales arroja resultados que confirman el análisis anterior a nivel votante individual. Utilizando QGIS se correlacionaron dos capas de la Provincia de Buenos Aires, una que captura el porcentaje de población que vive en villas y asentamientos por circuito y otra que vuelca los resultados electorales por circuito de las Elecciones 2017 (categoría Senador Nacional por la Provincia de Buenos Aires). Para confeccionar la capa de porcentaje de familias en villas y asentamientos por radio censal se utilizó la cantidad de hogares por circuito electoral del CENSO 2010 y la cantidad de Familias que habitan en villas y asentamientos del Relevamiento 2016 de TECHO (http://relevamiento.techo.org.ar/). Como espacialmente los límites de villas y asentamientos no coinciden con los de los circuitos, se realizó una suma proporcional de dichos datos según los circuitos que geográficamente les correspondían. Los resultados para los 1083 circuitos electorales de la Provincia de Buenos Aires electorales provienen de la Dirección Nacional Electoral. La Tabla 4 muestra los resultados de la correlación entre porcentaje de hogares en villas y asentamientos por circuito electoral de la Provincia de Buenos Aires y porcentaje de voto a los distintos partidos. Se comparan los resultados electorales en un total de 1083 circuitos electorales. 


\section{Tabla 4}

Coeficientes de correlación entre porcentaje de hogares en villas por circuito y porcentaje de votos en la elección por Senador Nacional

(PBA 2017)

\begin{tabular}{|l|r|}
\hline & \% Hogares en villas \\
\hline PJ K & 0,4260 \\
\hline Cambiemos & $-0,3894$ \\
\hline PJ no K & $-0,0288$ \\
\hline
\end{tabular}

Fuente: elaboración propia con QGIS en base a CENSO (2010), TECHO (2016) y Dirección Nacional Electoral.

El porcentaje de hogares en villas se correlaciona positivamente y de manera alta con el voto al PJ K $(0,43)$. Por el contrario, la correlación con Cambiemos es, graficando la mentada grieta, negativa y alta $(-0,39)$. Estos coeficientes son estadísticamente significativos al $99 \%$. Pero lo interesante es que la correlación también es negativa en el caso del PJ no K. Aunque este coeficiente es muy pequeño, y por lo tanto no significativo, ilustra que la base del voto al PJ no K es distinta a la del PJ K. Una vez más la evidencia apunta a que la base electoral del peronismo está fragmentada socialmente.

La Tabla 5 ilustra estas correlaciones. De los 338 circuitos del Conurbano Bonaerense 128 no tienen población en villas y el FPV solo ganó en el $14 \%$ de estos (18), mientras que ganó en el $76 \%$ de los circuitos que tienen más del $20 \%$ de las familias en villas, en 47 de 62 . A medida que aumenta el porcentaje de familias en villa aumenta el porcentaje de circuitos en los que triunfa el FPV. Lo inverso ocurre con Cambiemos mientras que el PJ no K no triunfó en ninguno de los circuitos.

\section{Tabla 5}

Circuitos del Conurbano en los que triunfó el FPV para Senador 2017 según porcentaje de hogares en villas y asentamientos

\begin{tabular}{|l|r|r|c|}
\hline$\%$ Familias en Villas & N $^{\circ}$ de Circuitos & Ganó FPV & $\%$ \\
\hline $0 \%$ & 128 & 18 & 0.140625 \\
\hline 0.1 a $10 \%$ & 90 & 41 & 0.45555556 \\
\hline 11 a $20 \%$ & 58 & 31 & 0.53448276 \\
\hline Más de $20 \%$ & 62 & 47 & 0.75806452 \\
\hline Total Circuitos & 338 & 137 & 0.40532544 \\
\hline
\end{tabular}

Fuente: elaboración propia con QGIS en base a CENSO (2010), TECHO (2016) y Dirección Nacional Electoral. 


\section{Conclusión}

Desde la crisis de 2001 hasta la actualidad, el peronismo no se ha presentado unificado en ninguna elección presidencial. En 2015 sufrió una dura e inesperada derrota a pesar de que, en la elección general, los candidatos de extracción peronista, Daniel Scioli, Sergio Massa y Adolfo Rodríguez Saá, sumaban más del $60 \%$ de los votos. Nos encontramos en tiempos preliminares a las elecciones presidenciales 2019, pero ya todo hace prever que al menos habrá dos candidatos de filiación peronista, uno por el Peronismo K y otro por el Peronismo no K. Existe una natural tendencia a adjudicar esta fragmentación electoral del peronismo a características personales de sus candidatos; se trataría fundamentalmente de un problema de liderazgo y egos exacerbados. Sin negar la existencia de este tipo de problemas, el presente artículo señala causas estructurales de la falta de unidad electoral del peronismo. Argumenta que, egos aparte, la grieta social genera una demanda por candidatos peronistas de distintos perfiles ideológicos que dispersa, por lo tanto, su oferta.

De las varias décadas de atraso económico y la reforma de los 90 que eclosionó en 2001 emergieron nuevas realidades y actores sociales, rompiéndose la relativamente homogénea sociedad salarial argentina. La evidencia presentada en este artículo muestra no solo cómo dicha fragmentación da sustento estructural a la grieta entre el FPV y Cambiemos, sino que señala también una grieta en la base electoral del peronismo. Al tomar los votantes con educación secundaria o menor, nos encontramos con que la base electoral del PJ K difiere de aquella del PJ no K. Los votantes del PJ K tienden más a vivir en villas y asentamientos, ser trabajadores informales y percibir planes que los votantes del Peronismo no K. Estas discontinuidades sociales contribuyen a una demanda diversificada de candidatos peronistas fragmentando su unidad electoral.

La teoría y evidencia presentada sostienen así que el problema de unidad del peronismo no se debe simplemente a un problema de liderazgo o agencia política sino a la dificultad de representar a sectores con intereses diversos. Se podría especular que el peronismo probablemente no hubiera perdido elecciones claves, en las últimas dos décadas, si sus candidatos hubieran logrado unificarse. Pero los votantes que se definen como peronistas sostienen hoy demasiado frecuentemente reclamos contradictorios. No es fácil reconocer la legitimidad del piquete y garantizar la libre circulación de los trabajadores, ni sostener la importancia de los planes sociales y prometer no cobrar ganancias. Todos estos, reclamos hechos por la base electoral peronista. No argumentamos que sea imposible representarlos, de hecho ya ha acontecido a lo largo de la primera década del siglo XXI, pero planteamos que la fragmentación social instaura un desafío a la unidad peronista. 
Obviamente, teniendo en cuenta la hipótesis, la evidencia presentada es solamente la mejor disponible. La elección presidencial de 2019 podría presentar en este sentido una buena ocasión para recoger una muestra representativa de los votantes de los sectores que conforman la base electoral histórica del peronismo y avanzar en esta línea de investigación. Una base con la cantidad de observaciones necesarias para tener poder estadístico y que incluya cómo votaron los sectores de ingresos y educación medios y bajos, los beneficiarios de planes, los habitantes en villas y los trabajadores formales, informales y desocupados sería un gran aporte al estudio de los clivajes sociales de los partidos políticos en la Argentina de hoy. Sobre todo, porque pareciera que el problema va a seguir vigente en las elecciones presidenciales de 2019. No sería extraño que los candidatos de extracción peronista obtuvieran más del $50 \%$ de los votos pero tampoco que sean, al menos, dos. La marcha proclama «todos unidos triunfaremos...» y pareciera ahí estar el problema del partido peronista.

\section{Referencias bibliográficas}

Abal Medina, P. (9 de mayo de 2016). Las formas políticas del trabajo [en línea]. Universidad Nacional de San Martín, Revista Anfibia. Disponible en: http:// www.revistaanfibia.com/ensayo/las-formas-politicas-del-trabajo/ Fecha de consulta: $10 / 06 / 2018$.

Bonfiglio, J., y Vera, J. (2018). Condiciones materiales de vida. Hábitat, pobreza y desigualdad en los hogares urbanos de Argentina (2010 - 2017) [en línea]. Pontificia Universidad Católica Argentina. Disponible en: http://uca.edu.ar/es/ noticias/condiciones-materiales-de-vida.-habitat-pobreza-y-desigualdad-en-loshogares. Fecha de consulta: 10/10/2018.

Burdman, J. (11 de septiembre de 2017). El peronismo tiene un problema de liderazgo, no de unidad [en línea]. Entrevista por Agustín Cesio y Diego Sánchez. Revista Zoom. Disponible en: https://revistazoom.com.ar/el-peronismo-tiene-un-problema-de-liderazgo-no-de-unidad/ Fecha de consulta: 17/06/2018.

Catterberg, E. y Braun, M. (1989). Las elecciones presidenciales argentinas del 14 de mayo de 1989: La ruta a la normalidad. Desarrollo Económico, 29(115), 361-374.

Catterberg, E. (1985). Las elecciones del 30 de octubre de 1983. El surgimiento de una nueva convergencia electoral. Desarrollo Económico 25(98), 259-267.

Colazingari, S., y Palermo, V. (2016). Peronismo clásico y peronismo plebeyo: El populismo de la globalización. Temas y Debates, 32, 27-49.

Collier, R., y Collier, D. (1991). Shaping the political Arena. Critical junctures, the labor movement, and regimen dynamics in Latin America. Princenton: Princenton University Press. 
Etchemendy, S., y Collier, R. (2007). Down but Not Out: Union Resurgence and Segmented Neocorporatism in Argentina (2003-2007). Politics E' Society, 35(3), 363-401.

Fidanza, E. (2017, 30 de diciembre). La estrategia que puede destronar al peronismo [en línea]. La Nación. Disponible en: https://www.lanacion.com.ar/2096598-laestrategia-que-puede-destronar-al-peronismo. Fecha de consulta: 2/06/2018.

Franceschelli, I. y Ronconi, L. (2009). The effect of workfare policy on social movement mobilizations. Economics Letters, 105(3), 315-317.

Garay, C. (2007). Social Policy and Collective Action: Unemployed Workers, Community Associations, and Protest in Argentina. Politics E Society, 35(2), 301328.

Gestión Sindical. (23 de marzo de 2018). Los movimientos sociales quieren sumarse a la estructura de la CGT para fortalecer sus reclamos [en línea]. Disponible en: https://gestionsindical.com/los-movimientos-sociales-quieren-sumarse-a-la-estructura-de-la-cgt-para-fortalecer-sus-reclamos/ Fecha de consulta: 20/08/2018.

Guadagni, A. (2015). Hay más estudiantes y egresados, pero crece la desigualdad. Centro de Estudios de la Educación Argentina, Universidad de Belgrano, 33, 1-14.

Levitsky, S. (2003). Transforming labor-based parties in Latin America: Argentine Peronism in comparative perspective. Cambridge, U.K: Cambridge University Press.

Murillo, M. (2017). La democracia argentina, entre vaivenes e incrementalismo. Revista SAAP, 11(2), 10-30.

Natanson, J. (Septiembre de 2017). ¿Hegemonía Macrista? [en línea]. Le Monde Diplomatique. Disponible en: https:/www.eldiplo.org/219-la-clase-media-en-tiempos-de-macri/hegemomia-macrista/\#n_2 Fecha de consulta: 20/06/2018.

Novaro, M. (31 de Agosto de 2017). El peronismo está herido, pero no de muerte [en línea]. La Nación. Disponible en: https://www.lanacion.com.ar/2058117-elperonismoesta-herido-pero-no-de-muerte. Fecha de consulta: 20/06/2018.

Rodríguez, K. (2013). Nota Técnica N ${ }^{\circ} 74$ EMPLEO E INGRESOS, Correspondiente al Informe Económico $\mathrm{N}^{\circ} 84$ Tercer Trimestre de 2013. Ministerio de Hacienda.

Semán, P. (Julio de 2017) La grieta opositora [en línea]. Le Monde Diplomatique. Disponible en: https://www.eldiplo.org/217-la-disputa-por-el-liderazgo/la-grieta-opositora/ Fecha de consulta: 20/06/2018.

Ronconi, L. (2009). Estimates of the Benefit Incidence of Workfare. Economia:Journal LACEA 9(2), 129-145.

Torre, J. (2012). Ensayos sobre movimiento obrero y peronismo. Buenos Aires, Argentina: Siglo Veintiuno Editores.

Torre, J. (2017). Los huérfanos de la política de partidos revisited. Revista SAAP, 11(2), $10-30$.

Zarazaga, R. (2017, 13 de mayo). Los CEO's entendieron que, si el barco se hunde, no hay un buen camarote [en línea]. La Política Online. Disponible en: https:// www.lapoliticaonline.com/nota/105445-los-ceos-entendieron-que-si-el-barco-sehunde-no-existe-un-buen-camarote/ Fecha de consulta: 14/06/2018. 


\title{
Palabras clave
}

peronismo - elecciones - fragmentación social - Argentina - grieta

\section{Keywords}

peronism - elections - social fragmentation - Argentina - polarization

\begin{abstract}
Since the 2001 Argentine crisis, Peronist Party has never run unified for presidential elections. The present article evaluates the causes of this lack of unity. It stands that the traditional base of peronist voters has suffered a progressive social fragmentation, which explains the electoral dispersion of its candidates. The analysis of different data sets offers evidence of this fragmentation as well as its electoral implications, focusing on three dimensions of voters: occupational status, social programs benefits and habitat exclusion.
\end{abstract}

\section{Apéndice $^{1}$}

Este apéndice describe cada una de las cinco muestras utilizadas.

\section{Argentine Panel Election Study ${ }^{2}$}

En 2015, el investigador Noam Lupu coordinó una encuesta de tipo panel, para estudiar las preferencias y opiniones de los electores durante las elecciones presidenciales en Argentina.

\subsection{Diseño de la muestra}

Se realizaron dos «olas» de encuestas cara a cara en todo el territorio nacional. La primera ola se realizó previo a las elecciones presidenciales, entre el 24 de junio y el 7 de agosto de $2015^{3}$. La segunda ola, entre el 21 de noviembre de 2015 y el 30 de diciembre de 2015. La primera ola abarcó a 1.149 ciudadanos argentinos mayores de 18 años. Se realizó una muestra

Disponible online en www.cias.org.ar

Disponible online en APES: http://www.noamlupu.com/data.html

Las PASO se realizaron el 9 de agosto de 2015. Las elecciones generales tuvieron una primera vuelta el 25 de octubre de 2015, y una segunda vuelta el 22 de noviembre de 2015 . 
estratificada y multietápica. En primer lugar, se seleccionaron 18 ciudades del país. Para cada ciudad, se utilizaron procedimientos probabilísticos, y una vez seleccionados los hogares, se utilizaron cuotas de sexo y edad. La segunda ola se propuso re-encuestar a todos aquellos que respondieron a la primera ola. La tasa de respuesta alcanzó al $68 \%$. Para compensar dicha situación, se agregaron 626 encuestados seleccionados bajo los mismos criterios descritos líneas arriba. En total, la segunda ola alcanzó 1406 casos.

\subsection{Construcción de variables y procesamiento de los datos}

Educación alta: 0 «Bajo», 1 «Alto». Se utilizaron las variables P89b (ola 1) y P102_w2 (ola

2). Se considera «Bajo» a todos aquellos encuestados con nivel educativo igual o inferior a Secundario Completo.

Formal: 0 «Informal», 1 «Formal». Se utilizaron las variables P93, P95, P102 y P105 (ola 1); y las variables P105_w2, P107_w2, P113_w2 y P115_w2 (ola 2). Formal incluye trabajadores del Estado o empresas del Estado; trabajadores en el sector privado, que tienen descuento jubilatorio; dueños o socios de empresa inscriptos y con pago al día en AFIP; trabajadores por cuenta propia inscriptos y con pago al día en AFIP. Informal incluye trabajadores en el sector privado que no tienen descuento jubilatorio; dueños o socios de empresa no inscriptos en AFIP o inscriptos pero que no realizan sus pagos regularmente; trabajadores por cuenta propia no inscriptos en AFIP o inscriptos pero que no realizan sus pagos regularmente; trabajadores no remunerados o sin pago.

Plan social: 0 «No cobra plan», 1 «Cobra plan». Se utilizaron las variables P120, P121 y P122 (ola 1); y las variables P131_w2, P132_w2 y P133_w2 (ola 2). Se consideran que cobran planes sociales a todos aquellos que respondieron que él o alguna persona de su hogar son beneficiarios de un plan social, AUH o Moratoria Previsional.

Voto FPV: 0 «PJ no K + Cambiemos», 1 «FPV-UC». Se utilizaron las variables P32_1 y P32_2 (ola 1); y las variables P27_abierta_w2 y P27_cerrada_w2 (ola 2). Se consideran votantes de «PJ no K» a quienes manifiestan su voto efectivo (ola 2) o intención de voto (ola 1) a Sergio Massa, José Manuel de la Sota o Adolfo Rodríguez Saá, votantes de «FPV-UC» a quienes manifiestan su intención de voto (ola 1) o voto efectivo (ola 2) a Daniel Scioli y votantes de Cambiemos a quienes manifiestan su voto efectivo (ola 2) o intención de voto (ola 1) a Mauricio Macri, Elisa Carrió o Ernesto Sanz. 


\section{Isonomía Consultores}

Isonomía es una consultora de Opinión Pública. En el marco de una encuesta nacional a realizarse en agosto de 2017, en conjunto con el CIAS se incorporaron algunas preguntas orientadas a responder la hipótesis del presente proyecto de investigación.

\subsection{Diseño de la muestra}

Se realizó una encuesta nacional de 1000 casos entre el 30 de agosto de 2017 y el 7 de septiembre de $2017^{4}$. Se encuestaron a ciudadanos argentinos, mayores de 16 años, en condiciones de votar en la localidad donde se encontraban a la hora de realizarse el sondeo. Se realizaron encuestas cara a cara en 77 localidades del territorio nacional (CABA, 46 localidades de Provincia de Buenos Aires, 30 del resto del país). En cada localidad se formaron Puntos Muestra - PM (grupos de 9 manzanas), y se realizó un sorteo aleatorio simple. Dentro de cada PM sorteado se tomaron entre 8 y 10 casos, sorteando aleatoriamente los hogares a encuestar. Sólo se realizó una encuesta por hogar.

\subsection{Construcción de variables y procesamiento de los datos}

En relación a este estudio, se tomaron únicamente 592 casos, que corresponden a Provincia de Buenos Aires, ya que sólo a dichos encuestados se les preguntó por el voto ${ }^{5}$. Para la construcción de las variables de interés, se utilizaron las siguientes preguntas y criterios:

Educación alta: variable «educación», se toma pregunta del cuestionario y se categoriza de igual manera que en la base anterior.

Formal: variables p58, p59 y educación (preguntas 53, 53A y d, del cuestionario). Formal incluye trabajadores del Sector Público; trabajadores del sector privado en relación de dependencia que el empleador les paga la obra social; trabajadores que trabajan por su cuenta y tienen empleados; trabajadores que trabajan por su cuenta sin empleados y son profesionales (universitario completo o superior). Informal incluye a trabajadores del sector privado en relación de dependencia que el empleador no les paga la obra social; Trabajadores por su cuenta sin empleados con nivel educativo inferior a universitario completo; trabajadores que hacen changas.

Posterior a las PASO, ocurridas el 13 de agosto de 2017.

Dado que se trató de elecciones intermedias, la pregunta por el voto a senador nacional en las PASO 2017 sólo refiere a PBA. No se realizó una adaptación de una misma pregunta para otras localidades. 
Plan social: variable p60 (pregunta 54 del cuestionario). Se consideran que cobran planes sociales a todos aquellos que respondieron que él o alguna persona de su hogar son beneficiarios de un plan social.

Voto FPV: variable p47 (pregunta 41 del cuestionario). Se consideran votantes del «PJ no K» a quienes manifiestan haber votado para senador nacional por PBA en las PASO 2017 a Sergio Massa o Florencio Randazzo, votantes de «FPV-UC» a quienes manifiestan haber votado a Cristina Fernández de Kirchner y votantes de Cambiemos a quienes manifiestan haber votado a Esteban Bullrich.

\section{Encuesta CIAS}

De manera complementaria con la encuesta de Isonomía, el equipo del CIAS adaptó una versión reducida del mismo cuestionario para realizarlo en villas y asentamientos precarios del conurbano.

\subsection{Diseño de la muestra}

Se realizaron 204 encuestas en villas y asentamientos precarios de 7 localidades del conurbano. Se seleccionaron tres localidades de la Tercera Sección Electoral (Lanús, Quilmes y La Matanza), cuatro localidades la Primera Sección Electoral (San Martín, San Miguel, Merlo y Moreno). Se realizaron entre 26 y 36 encuestas por localidad, según las posibilidades de cada encuestador. De cada localidad, se seleccionó 1 villa o asentamiento precario, acorde a las posibilidades de cada encuestador. Dada la dificultad adicional que tiene realizar encuestas en este tipo de lugares, el muestreo fue utilizando una técnica tipo «reloj». Se seleccionó un punto de inicio, lo más nodal posible, y el encuestador caminó en el sentido de las agujas del reloj, dejando un hogar de espacio al realizarse una encuesta efectiva (es decir, no se encuestaron hogares que comparten medianera). Se realizó un solo caso por hogar. A su vez, cada 10 casos, se trató de mantener una cuota de 5 varones y 5 mujeres y 343 en proporción de edad ( 16 a 29 - 30 a 49 - y 50 o más). Sin embargo, dicha cuota se aplicó de manera orientativa, dando prioridad a alcanzar un mínimo de 25 casos.

\subsection{Construcción de variables y procesamiento de los datos}

Dado que se utilizó una versión reducida del cuestionario de Isonomía, las variables de estudio fueron construidas utilizando las mismas preguntas y criterios. Adicionalmente, esta nueva encuesta permitió incorporar la variable:

Villa miseria: 0 «No Villa», 1 «Villa». 


\section{Marangoni (MyR Asociados)}

Gustavo Marangoni, director de MyR Asociados, colaboró a su vez con la presente investigación. A pedido del CIAS se incorporaron algunas preguntas en una encuesta realizada por la consultora en PBA.

\subsection{Diseño de la muestra}

Se realizaron 2420 encuestas telefónicas en la Provincia de Buenos Aires a personas mayores de 18 años, entre el 15 y el 17 de octubre de 2017 (previo a las elecciones generales, realizadas el 22 de octubre). Acorde con la base de datos, se dispararon llamadas a 120.000 números telefónicos en toda la provincia, de los cuales se obtuvo respuesta completa en los 2420 seleccionados.

\subsection{Construcción de variables y procesamiento de los datos}

Educación alta: pregunta P3 del cuestionario.

Formal: preguntas P8 y P3 del cuestionario. Formal incluye trabajadores del sector público; trabajadores del sector privado en relación de dependencia; trabajadores por cuenta propia con empleados; trabajadores por cuenta propia sin empleados y con nivel educativo universitario o superior. Informal incluye trabajadores por cuenta propia sin empleados con nivel educativo inferior a universitario; trabajadores que hacen changas. Es relevante aclarar que a aquellos que responden que trabajan «en el sector privado en relación de dependencia» no se les pregunta si el empleador les paga o no la obra social.

Plan social: pregunta P9 del cuestionario. Con respecto a esta pregunta, vale aclarar que se excluyó de la misma a todos aquellos que respondieron trabajar en el sector público y en el sector privado en relación de dependencia.

Voto FPV: pregunta P7 del cuestionario. Se consideran votantes del «PJ no K» a quienes manifiestan su voto efectivo en las PASO 2017 por senador nacional de PBA, a Sergio Massa o Florencio Randazzo, votantes «FPV-UC» a Cristina Fernández de Kirchner y votantes «Cambiemos» a Esteban Bullrich.

\section{Encuesta Lanús}

En colaboración con un equipo territorial de Lanús se coordinó desde el CIAS la implementación de una encuesta de imagen política en dicho distrito. A raíz de dicha colaboración, se incorporaron preguntas orientadas al presente proyecto de investigación. 


\subsection{Diseño de la muestra}

Se realizaron encuestas en todo el distrito de Lanús a ciudadanos argentinos o extranjeros mayores de 16 años en condiciones de votar en dicho distrito, entre el 19 y el 29 de septiembre de 2018. Se realizó una muestra estratificada por localidad (Lanús tiene 6 localidades), estimando las encuestas a realizar en cada localidad según su población (Censo 2010). Una vez realizado este cálculo, a través del software geográfico QGIS se arrojaron puntos aleatorios en cada localidad (calculando que por cada punto, se realizarían 15 encuestas). De tal manera, se arrojaron 80 puntos aleatorios en todo el distrito. En la manzana que cayó cada punto, se determinó una esquina de inicio. Dicho punto constituyó un Punto Muestral. En cada uno de estos puntos se indicaba al encuestador una vivienda de inicio (número aleatorio entre 1 y 9) y un salto de selección (10, 15 o 20 según densidad poblacional estimada de la manzana). Cada encuestador, una vez realizada una encuesta efectiva, debía saltar 10, 15 o 20 viviendas, para realizar la siguiente encuesta, caminando en dirección contraria a las agujas del reloj. A su vez, a las 8 manzanas que rodean a la manzana de inicio, se les asignó un número, donde el encuestador debía continuar el recorrido hasta alcanzar las 15 encuestas efectivas. Se alcanzó el número de 830 encuestas efectivas (el objetivo inicial apuntaba a las 1200, dando una tasa de cumplimiento del objetivo del $69 \%$ ). La tasa de respuesta fue del $45 \%$.

\subsection{Construcción de variables y procesamiento de los datos}

Para la construcción de las variables de interés, se utilizaron las mismas preguntas y criterios utilizados en los cuestionarios de Isonomía y CIAS:

Educación alta: pregunta del cuestionario.

Formal: preguntas d, 15 y 16.

Plan Social: pregunta 18 del cuestionario.

Voto FPV: pregunta 23 del cuestionario. La diferencia con respecto a Isonomía y CIAS radica en que refiere al voto efectivo para las elecciones de octubre de 2017.

Villa miseria: pregunta a.3 del cuestionario. Dado que la presente encuesta contempló villas y asentamientos precarios, se incluyó un campo para que complete el encuestador «Si» (para las encuestas realizadas en villas), «No» (para no villas). 
Revista SAAP · Vol. 13, № 1

5.3 Resultados utilizando exclusivamente la Encuesta Lanús

\section{Gráfico 4}

Porcentaje que vota al FPV

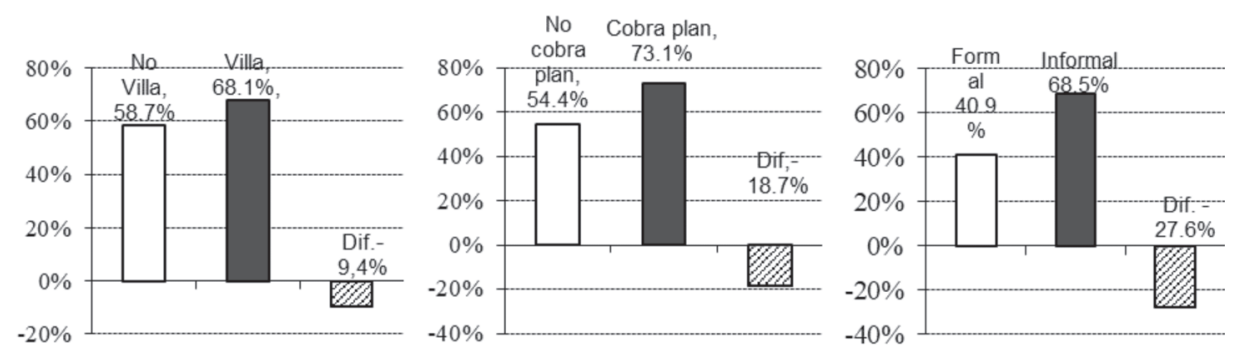

